\title{
WELL-POSEDNESS AND EXPONENTIAL DECAY FOR A LAMINATED BEAM IN THERMOELASTICITY OF TYPE III WITH DELAY TERM
}

\author{
MADANI DOUIB, SALAH ZITOUNI, and ABDELHAK DJEBABLA
}

\begin{abstract}
In this article, we study the well-posedness and asymptotic behaviour of solutions to a laminated beam in thermoelasticity of type III with delay term in the first equation. We show that the system is well-posed by using LumerPhilips theorem and prove that the system is exponentially stable if and only if the wave speeds are equal.
\end{abstract}

MSC 2010. 35B40, 35L56, 74F05, 93D20.

Key words. Laminated beam, thermoelasticity of type III, delay term, exponential decay.

\section{REFERENCES}

[1] T.A. Apalara, Uniform stability of a laminated beam with structural damping and second sound, Z. Angew. Math. Phys., 68 (2017), 1-16.

[2] A. Benaissa, A. Benguessoum and S.A. Messaoudi, Energy decay of solutions for a wave equation with a constant weak delay and a weak internal feedback, Electron. J. Qual. Theory Differ. Equ., 2014 (2014), 1-13.

[3] M.M. Chen, W. J. Liu and W. C. Zhou, Existence and general stabilization of the Timoshenko system of thermo-viscoelasticity of type III with frictional damping and delay terms, Adv. Nonlinear Anal., 7 (2018), 547-569.

[4] R. Datko, J. Lagnese and M.P. Polis, An example on the effect of time delays in boundary feedback stabilization of wave equations, SIAM J. Control Optim., 24 (1986), 152-156.

[5] A. Djebabla and N.E. Tatar, Exponential stabilization of the Timoshenko system by a thermo-viscoelastic damping, J. Dyn. Control Syst., 16 (2010), 189-210.

[6] S. Drabla, S.A. Messaoudi and F. Boulanouar, A general decay result for a multidimensional weakly damped thermoelastic system with second sound, Discrete Contin. Dyn. Syst. Ser. B, 22 (2017), 1329-1339.

[7] M. Ferhat and A. Hakem, On convexity for energy decay rates of a viscoelastic wave equation with a dynamic boundary and nonlinear delay term, Facta Univ. Ser. Math. Inform., 30 (2015), 67-87.

[8] J.A. Goldstein, Semigroups of linear operators and applications, Oxford Mathematical Monographs, The Clarendon Press, Oxford University Press, New York, 1985.

[9] S.W. Hansen, A model for a two-layered plate with interfacial slip. In: Control and estimation of distributed parameter systems: nonlinear phenomena, Vorau, 1993, pp. 143-170, Internat. Ser. Numer. Math., Vol. 118, Birkhauser, Basel, 1994.

The authors thank the referee for his helpful comments and suggestions.

DOI: $10.24193 /$ mathcluj.2021.1.06 
[10] S.W. Hansen and R. Spies, Structural damping in laminated beams due to interfacial slip, Journal of Sound and Vibration, 204 (1997), 183-202.

[11] J. Hao and P. Wang, Asymptotical stability for memory-type porous thermoelastic system of type III with constant time delay, Math. Methods Appl. Sci., 39 (2016), 3855-3865.

[12] J. Hao and P. Wang, Exponential decay of solution to the viscoelastic porous-thermoelastic system of type III with boundary time-varying delay, Math. Methods Appl. Sci., 39 (2016), 3659-3668.

[13] M. Kafini et al., Well-posedness and stability results in a Timoshenko-type system of thermoelasticity of type III with delay, Z. Angew. Math. Phys., 66 (2015), 1499-1517.

[14] W.J. Liu, K.W. Chen and J. Yu, Existence and general decay for the full von Kármán beam with a thermo-viscoelastic damping, frictional dampings and a delay term, IMA J. Math. Control Inform., 34 (2017), 521-542.

[15] W.J. Liu and W.F. Zhao, Stabilization of a thermoelastic laminated beam with past history, Appl. Math. Optim., 80 (2019), 103-133.

[16] W.J. Liu and W.F. Zhao, Exponential and polynomial decay for a laminated beam with Fourier's type heat conduction, Preprint.

[17] G. Li, X.Y. Kong and W.J. Liu, General decay for a laminated beam with structural damping and memory: the case of non-equal wave speeds, J. Integral Equations Appl., 30 (2018), 95-116.

[18] A. Lo and N.-E. Tatar, Stabilization of laminated beams with interfacial slip, Electron. J. Differential Equations, 2015 (2015), 1-14.

[19] Y. Luan, W. Liu and G. Li, Well-posedness and asymptotic stability to a laminated beam in thermoelasticity of type III, Preprint.

[20] S.A. Messaoudi and T.A. Apalara, General stability result in a memory-type porous thermoelasticity system of type III, Arab J. Math. Sci., 20 (2014), 213-232.

[21] S.A. Messaoudi and A. Fareh, Energy decay in a Timoshenko-type system of thermoelasticity of type III with different wave-propagation speeds, Arab. J. Math. (Springer), 2 (2013), 199-207.

[22] S.A. Messaoudi and B. Said-Houari, Energy decay in a Timoshenko-type system of thermoelasticity of type III, J. Math. Anal. Appl., 348 (2008), 298-307.

[23] M.I. Mustafa, On the decay rates for thermoviscoelastic systems of type III, Appl. Math. Comput., 239 (2014), 29-37.

[24] S. Nicaise and C. Pignotti, Stability and instability results of the wave equation with a delay term in the boundary or internal feedbacks, SIAM J. Control Optim., 45 (2006), $1561-1585$.

[25] S. Nicaise and J. Valein, Stabilization of second order evolution equations with unbounded feedback with delay, ESAIM Control Optim. Calc. Var., 16 (2010), 420-456.

[26] S. Nicaise, C. Pignotti and J. Valein, Exponential stability of the wave equation with boundary time-varying delay, Discrete Contin. Dyn. Syst. Ser. S, 4 (2011), 693-722.

[27] A. Pazy, Semigroups of linear operators and applications to partial differential equations, Vol. 44, Applied Math. Sciences, Springer-Verlag, New York, 1983.

[28] J.E. Muñoz Rivera and R. Racke, Mildly dissipative nonlinear Timoshenko systemsglobal existence and exponential stability, J. Math. Anal. Appl., 276 (2002), 248-278.

[29] N.E. Tatar, Stabilization of a laminated beam with interfacial slip by boundary controls, Bound. Value Probl., 169 (2015), 1-11.

[30] J.-M. Wang, G.-Q. Xu and S.-P. Yung, Exponential stabilization of laminated beams with structural damping and boundary feedback controls, SIAM J. Control Optim., 44 (2005), 1575-1597.

[31] S. Zitouni, A. Ardjouni, M.B. Mesmouli and R. Amiar, Well-posedness and stability of nonlinear wave equations with two boundary time-varying delays, Mathematics in Engineering, Science and Aerospace (MESA), 8 (2017), 147-170. 
[32] S. Zitouni, L. Bouzettouta, Kh. Zennir and D. Ouchenane, Exponential decay of thermoelastic-Bresse system with distributed delay, Hacet. J. Math. Stat., 47 (2018), $1216-1230$.

Received May 14, 2019

Accepted November 11, 2019
University of Annaba

Department of Mathematics, Faculty of Sciences P.O. Box 12, Annaba 23000, Algeria

Higher College of Teachers, Laghouat, Algeria

Department of Mathematics

E-mail: madanidouib@gmail.com

University of Souk Ahras

Department of Mathematics and Informatics

P.O. Box 1553, Souk Ahras 41000, Algeria

E-mail: zitsala@yahoo.fr

University of Annaba

Department of Mathematics, Faculty of Sciences

P.O. Box 12, Annaba 23000, Algeria

E-mail: adjebabla@yahoo.com 